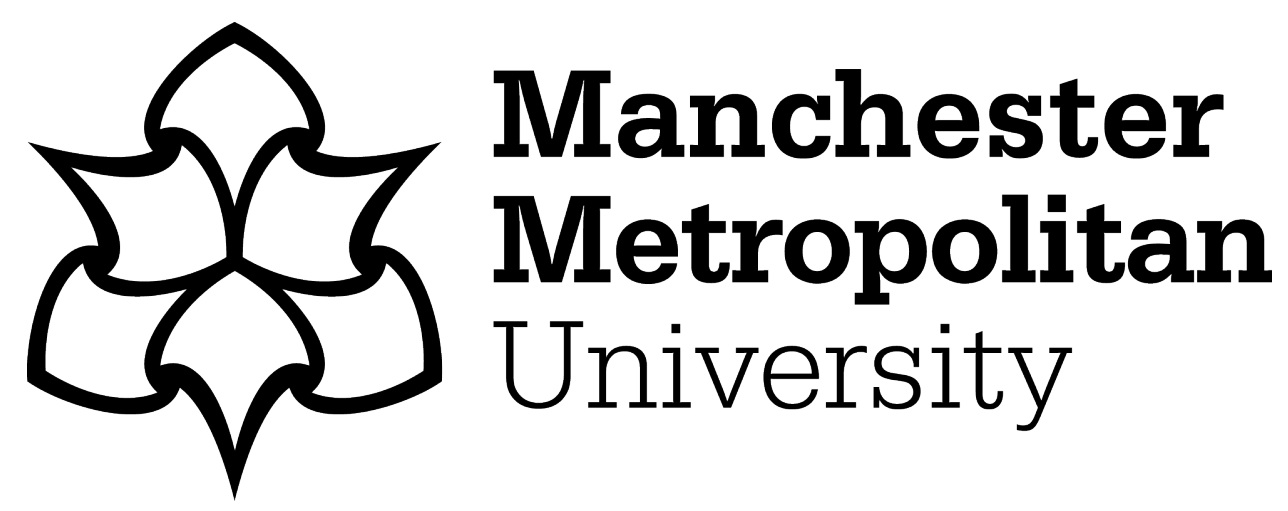

Leah, Caroline (2020) Approved Mental Health Professionals: A Jack of all Trades? Hybrid Professional Roles within a Mental Health Occupation. Qualitative Social Work, 19 (5-6). pp. 987-1006. ISSN 1473-3250

Downloaded from: https://e-space.mmu.ac.uk/623787/

Version: Accepted Version

Publisher: SAGE Publications

DOI: https://doi.org/10.1177/1473325019873385

Please cite the published version 


\title{
Approved Mental Health Professionals: A Jack of all Trades? Hybrid Professional Roles within
} a Mental Health Occupation

\begin{abstract}
This article presents findings from the Hybrid Identities Project (HIP) that investigated the professional role and identities of ten multi-professional Approved Mental Health Professionals (AMHPs) from social work, mental health nursing and occupational therapy backgrounds as hybrid professionals. Hybrid professionals are professionals of a mixed origin who work across several roles and areas of expertise within public services. AMHPs have a legal role within the Mental Health Act 1983 (2007) in England and Wales to plan the assessment of individuals who require care and treatment for a mental disorder. An intrinsic case study approach was undertaken with data generated through semi-structured interviews that examined professional hybridisation, illustrated through AMHPs' enactment of eight hybrid roles. The article contributes to empirical understandings of AMHP professional practice through advancing ideas about role hybridisation within a previously under-researched mental health occupation.
\end{abstract}

\section{Keywords}

Approved Mental Health Professional (AMHP) Role, Mental Health Social Work (MHSW), Hybrid Professional, Mental Health Roles, Mental Health Act Assessments

\section{Introduction and background}

The proportion of the European Union's population diagnosed with a mental disorder in any one year is $38.2 \%$ (164.8 million people). On average, $26 \%$ of people with mental illness in Europe are provided with treatment (Wittchen et al., 2011). The Mental Health Act (MHA) 1983 in England and Wales (DoH, 2008a) is currently undergoing review, due in part, to the increased number of 
individuals being compulsorily detained. In England and Wales, between 2015/16 there were 63,600 individuals detained under the MHA compared to 43,400 in 2005/6, an increase of 47\% (NHS Digital, 2017). In November 2018, there were estimated to be 3,667 AMHPs approved by local authorities (DHSC, 2018). Although the number of individual detentions has increased, conversely, the number of AMHPs has decreased (ADASS, 2018). Both mental health prevalence and legislative review influence how the AMHP role is practised. It is therefore timely to interrogate the role of the AMHP; a statutory role given to predominantly social workers, with less than $5 \%$ of other qualifying professionals, e.g. mental health and learning disability nurses, occupational therapists and chartered psychologists in England and Wales taking up the role (DHSC, 2018).

This article discusses findings on the hybrid roles AMHPs enacted, taken from a small-scale longitudinal qualitative study of the multi-professional AMHP role in England. The process by which AMHPs negotiate and craft roles has received little empirical attention thus far. Although, Morriss (2017) has commented on the invisibility of the AMHP role by considering the ways social work AMHPs worked in liminal spaces, occupying the gaps left by other professions; this article will offer further insights into the AMHP role, through the author's examination of multi-professional AMHPs as hybrid professionals. The examination of hybrid roles was developed from the work of Quirk et al., (2000), who investigated the multifarious roles Approved Social Workers (ASWs) performed.

Through the exploration of hybrid roles as a key concern the author will suggest AMHPs enact hybrid roles as an adaptive mechanism to manage Mental Health Act Assessments (MHAA) in complex organisational and professional encounters. In doing so, the article advances literature on hybrid roles by combining ideas about role hybridity within a previously under-research professional role and the broader institutions in which they are embedded for AMHP practice.

\section{The Role of the AMHP}

The statutory role of the AMHP was introduced in 2007 when the Mental Health Act 1983 was amended, replacing the previous role of the Approved Social Worker (DoH, 2008a). The Mental 
Health Act 1983 applies in England and Wales and most of the effects of the Act came into place in 2008. AMHPs have overall responsibility to coordinate assessments and manage compulsory admission to hospital for individuals in acute mental health crisis, involving several tasks, e.g. collaborating with other professionals, e.g. a psychiatrist, advising police to attend where there are risks to other people and arranging transport (usually an ambulance) to take the person to hospital (DoH, 2008a). Assessments are undertaken 365 days of the year, in a variety of locations, over a 24hour period. AMHPs assess a wide variety of people within a spectrum of mental disorder, such as those with a diagnosis of psychosis or dementia during MHA assessment. They work within a legal definition of mental disorder, emphasising a social perspective, on behalf of local authorities undertaking statutory functions and duties under the Act (DoH, 2008a).

The role of the AMHP is mirrored in other contexts, e.g. the Approved Social Worker in Northern Ireland (Mental Health (Northern Ireland Order, 1986); Mankelow et al, 2002) or within the Baker Act, Florida (1971) where a licensed mental health professional may initiate an involuntary examination that lasts for up to 72 hours. Other international contexts for the treatment of mentally disordered individuals tend to require legal and medical professionals to act as 'applicants'. In New Zealand, 'any person may complete an application asking the Director of Area Mental Health Services for an assessment of the person'. The assessment must be conducted by a psychiatrist, medical or nurse practitioner (section $9(3 \mathrm{a}, \mathrm{b})$ (The Mental Health (Compulsory Assessment and Treatment) Act, 1992). This context suggests the role of the AMHP in England and Wales is aligned to similar international roles that span legal, medical and social perspectives of mental health practice. Both the complexity of roles, and the broadening out of professionals occupying multiple roles, are features of modern health and social care systems that are enforced and enacted at systemic, institutional, group and individual levels in contemporary society (Noordegraaf, 2015). These features suggest that AMHPs could be conceptualised as hybrid professionals (Leah, 2018). 


\section{Theorising Professional Hybridity}

Hybridity is a complex concept, subject to numerous interpretations and operates on multiple levels. Within the sociology of professions, hybrid professionals are perceived as both occupying hybrid roles and complex identities (Croft et al., 2015; Spyridonidis et al., 2015) embedded in different professional groups (Byrkjeflot et al., 2014; Spyridonidis et al., 2015) and as an enactment of wider changes at individual level on professionals in public service (Waring, 2015). Hybridity further signals the liminal space between two or more original approaches (Walter, 2003; Croft et al., 2015; Waring, 2015; Morriss, 2017; Leah, 2018).

In terms of professional roles, hybridity is conceptualised as the mixing of two or more professional roles, e.g. the 'hybrid manager' in the medical profession (McGivern et al., 2015), or 'physician executives' in the USA (Hoff, 2000). Noordegraaf (2007) further defines hybrid professionals as professionals who cross-cut several professional roles or alternatively cross-cut traditional professional boundaries when they enact multiple roles. Professionals enact roles; thereby claiming professional jurisdiction over the roles enacted, with the language used to express the role, and values foregrounded suggesting salience with roles that can be adopted or discarded contextually (Quirk et al., 2000; Leah, 2018). The espoused enactment of roles is pivotal for understanding how professionals operate, how a profession wants to be seen and how a profession is seen by others (Evetts, 2002, 2006; Leah, 2018).

Reconfigurations of professional work are situated in socioeconomic, demographic, technological and cultural arenas that influence the nature of professional work (Noordegraaf, 2015). In practice, professionalism is complex and dynamic, affected by contexts, local and national and is creating hybridisation (Walter, 2003, Noordegraaf, 2007, 2015). The concept of 'hybridised professionalism' is an attempt to reinterpret professionalism and to reflect the contemporary landscape in which professionalism is practised (Noordegraaf, 2007, 2015). It is defined by a focus on professionals who are reflective practitioners, e.g. Schon's managers, and broadened out to include a less restricted use 
of the term professional that values 'artistic, intuitive processes which some practitioners do bring to situations of uncertainty, instability, uniqueness and values conflict' (Schon, 1983, p.49). It is a relational concept, which requires 'interdisciplinary knowledge and interactive skills' (Noordegraaf, 2007, p.775):

Hybrid professionalism connotes a 'new', more accessible, more democratised form of professionalism that includes what has come to be known as reflective practice (Evans, 2013, p.482).

Hybrid professionals are adept at operating within ambiguous public domains that are not easily organised. They can act in complex settings that have hybrid organisational forms (e.g. health and social care trusts). Their work is attached to circumstantial societal change that shows responses to contextual factors involving symbolic and cultural meaning making and 'their links with outside worlds are part of their professionalism' (Noordegraaf, 2007, p.771). In summary, hybridised professionalism is 'highly relevant in mixed occupations' (Noordegraaf, 2015) such as AMHPs, where meaningful connections are required between service users' public and private domains. Particularly, where issues are 'soft' and there are multifaceted interactions that require linking 'street level work' with organisational and professional decisions (Lipsky, 1980).

In this way, hybrid roles will be examined as roles enacted by AMHPs, who are of mixed occupational origin, in ways that illuminate inter-professional tensions, jurisdictional disputes, mediation and the blurring of professional boundaries. This article draws on Blomgren and Waks' (2015: p.79) definition of hybrid professionals, who are 'professionals who operate in broad knowledge areas, who have developed competence outside their main area of expertise...in situations characterised by institutional complexity', as conceptual lens through which data was interpreted.

\section{Methodology}

The Hybrid Identities Project (HIP) was informed by an intrinsic case study approach (Yin, 2014) and framed by Abbotts' argument that 'an effective historical sociology of professions must begin with 
case studies of jurisdictions' $(1988$, p.2). AMHP roles were explored through the narratives of ten AMHPs (social work $-\mathrm{n} .7$; nurse $-\mathrm{n} .2$; occupational therapy n.1 - see Table 1 ). The aim of the research was to purposively recruit AMHPs from all professional backgrounds, including chartered psychologists via heads of social work as introducers, however, there was no response from chartered psychologists AMHPs to the recruitment strategy. Participants were contacted by email, given Participant Information Sheets and ethical guidance, and asked to sign consent forms before interviews commenced. Participants were reminded at the start of interviews that they could withdraw from the research at any time. Ethics approval was gained from the University Ethics Committee, which classified the study as medium risk (PGR-73612820), with additional research and design approval received from three trust sites based in England where participants were employed. (This was in conjunction with University sponsorship and indemnity letters (Study Reference 14/25). Data was encrypted and stored in a secure cabinet on a password protected computer. Participants were given pseudonyms and anonymised. The inclusion criteria were that participants had been practising AMHPs for a minimum of two years. Seven participants identified as females and three as males. The participants were employed across a range of service areas and teams, including a dedicated AMHP hub to reflect the diversity of AMHP practice (see Table 1). The study took place between April 2014 - September 2017. The researcher was previously an ASW and Community Mental Health Team Manager and is a current AMHP educator. She perceived her insider status to be a strength of the study. Many researchers including DeVerteuil (2004) believe that insider researchers have an advantage when a study is about culture, including the culture of professional practice, because it enables researchers to share common values or experiences.

\section{Data collection and analysis}

Data was generated through semi-structured interviews conducted in three stages, at six monthly intervals and investigated perceptions of hybrid roles related to empirical research on the ASW and 
AMHP role (Quirk et al., 2000; Gregor, 2010; Morriss, 2017) and broader ideas of professional hybridisation (Noordegraaf, 2007, 2015; Oliver, 2015; Spyridonidis et al., 2015). Interviews were undertaken at workplaces, lasted approximately 60 minutes and were transcribed verbatim. This study drew on Quirk et al's., (2000) findings of the multifarious roles ASWs were found to perform by investigating how similar roles were enacted by AMHPs in the study.

Framework analysis (Ritchie and Spencer, 1994) was used to analyse the data with 'indexing' matched to an overarching conceptual framework (Macfarlane and O’Reilly, 2012). AMHP narratives were systematically compared and analysed in relation to espoused hybrid roles using comparative tables and coding to display, compare and show patterns between the data. Exemplar participant narratives were applied to construct hybrid roles. The process was iterative as the author moved back and forth between data and literature to develop conceptual categories, using induction and deduction to explain data. Initially, theory on professional identities, roles and professionality guided coding and analysis. Subsequently, theorisations concerning hybrid roles acted as a conceptual guide once multiple roles emerged within the data. Data was reanalysed until the point of saturation to explain the findings through a social constructivist lens (Vygotsky, 1980). Analysis was further influenced by the author's knowledge as an 'insider researcher' (Pillow, 2003).

\section{Findings}

This section will explore AMHP hybrid roles, using extracts from interview data, where it was evident that all participants espoused multiple 'invisible' roles in addition to the officially sanctioned role of the legal 'applicant' (DoH, 2008a). Participants espoused through complexity in working arrangements within and across AMHP jurisdictional boundaries how roles were foregrounded events, with some roles filling the spaces left vacant by other professional groups through liminality. Hybrid roles were used to influence other professionals and ultimately the course of the care and treatment 
outcomes for individuals' experiencing mental illness. The hybrid roles AMHP espoused are firstly discussed by briefly illustrating one example through the metaphor of 'wearing different hats'. This is followed by an examination of the multiple hybrid roles AMHPs contextually enacted in liminal spaces at the intersection of health and social care services. Pseudonym names for participants will be used hereafter. Tina suggested the AMHP role involved juggling different nested roles within the dynamics of a MHA assessment skilfully and sensitively:

I suppose it's true that you slip into different roles all of the time ....and as an AMHP you are 'wearing different hats'...you're the advocate, you're the caring person, you're the judge and I'm going to detain you, but I also care about you! (Tina, Interview 1).

Eight roles, which were conceptualised by the author, will now be examined in detail by illustrating the roles AMHP espoused within their daily practice. The first three roles were conceptualised by the author as legal roles, these were as follows; 'Quasi-Judge'; 'Detective'; and 'Legal Enforcer'. The role that operationalised the social perspective was the 'Custodian of Social Justice'. This was followed by interrelated advisory roles of 'Advocate', 'Educator' and 'Mediator'. Finally, the role of 'Therapist' is briefly discussed. These roles, developed from Quirk et al's study (2000) were either adopted by AMHPs or imposed upon them by other professionals whilst exercising their duties, mainly during community MHA assessments.

\section{Legal roles}

\section{'Quasi-Judge'}

The notion of AMHPs occupying quasi-judicial roles has been found previously (see Quirk et al., 2000; Gregor, 2010). In contrast to the conceptualisation of AMHPs as 'mini courts on legs' (Gregor, 2010: p.435), a more nuanced role was conveyed, where participants traversed dualistic functions that encompassed care and control, and where tensions between these dichotomies was enacted situationally and in routine ways. Kate stated:

...we're making judgements all the time...starting at MHA assessments. How we can do it, how we can coordinate it...whether someone is detained or not...we need to know the key bits of law, that influences and impacts upon your practice (Interview 3).

Here, Kate illustrated the legal aspect of her role. She made 'mini judgements' throughout her 
assessment with a final judgement made on whether she would detain or not the individual being assessed. She stated case law judgements were considered, describing how case law had changed the way that AMHPs must consult with a nearest relative in the 'Enfield Judgement' (TW v Enfield Borough Council, 2014).

Role enactment was visible in the ways other professionals perceived the quasi-judicial role to be occupied by AMHPs. Bernie narrated how a psychiatrist perceived her 'as the judge'; in the telling of the story, Bernie incorporated this judicial aspect into her own professional role. She expressed the psychiatrist's way of perceiving the role as 'quite useful', demonstrating her acceptance of perceiving the AMHP role in this way:

...he sees the AMHP as being the judge and that the two doctors have got to persuade the AMHP to sort of settle on their side of the fence if you will. And I thought that's quite useful ...because whether you're doctor, the person's care coordinator or the AMHP, there's a lot of persuading that has got to be done and whoever does the best persuading it's about what the outcome is (Bernie, Interview 1).

Interestingly, the AMHP role was perceived to be more complex than that of a judge, due to the everevolving situations of assessment and risk management where participants were making live judgements that required negotiation, often in complex highly emotionally charged and risky environments:

Judges look at that if it goes to court, but we're doing that on a day-to-day basis and in practice, we are making those decisions (Kate, Interview 3 ).

Matthew related how the quasi-judicial role was nuanced, we 'get it right from the mouth' and how within this role AMHPs were making informed judgements, responding to various people within a MHAA, to make the decision regarding detention:

Judges respectfully are in a controlled environment, we are looking out, they're sitting still and listening. We've got a better ability to influence, make decisions.... we've got a live situation, and we've got a better picture (Matthew, Interview 3).

Participants' narratives showed how they provided legal advice and of their command of legal frameworks to psychiatrists, section 12 doctors, GPs, police and ambulance staff in situations characterised by risk. 


\section{'Detective'}

The role of 'detective' was enacted when participants gathered detailed written and verbal evidence before, during and following MHA assessments and when they 'interviewed' relevant parties e.g. psychiatrists, to understand individuals' mental health presentations. Elizabeth stated within the role:

You do weigh the evidence, and some of the evidence isn't great to be quite honest from other professionals, as well as being a judge (you're) also like a detective... (But) a lot of the evidence is not forthcoming really, so you have to dig for the evidence, and you have to make sure you've been thorough, going through records and asking questions when you think something's been missed (Interview 3).

Additionally, as 'detectives' participants understood and reconciled contradictory information that was held in relation to service users' historical and current medical and social circumstances. The skill of participants was to detect the different perspectives that various parties involved in MHA assessment communicated, to ensure that the evidence upon which decisions were made in relation to the individual's care and treatment needs was holistic, rather than one-dimensional. This role was important for participants due to working in a climate where defensible decisionmaking was legally required and the consequences of not gathering evidence could lead to litigation. This litigation was present in a variety of case law judgements where AMHPs had omitted this important element of their work.

\section{'Legal Enforcer'}

A 'legal enforcer' compels observance of or compliance with law, providing robust justification for legal actions and taking an authoritative stance when other professionals attempt to transgress the duties under the MHA (DoH, 2008a):

I think we enforce law, we tell people what they can and can't do. We can force our way into your home, very much so, and we're very much seen in that way and I'm not surprised (Annette, Interview 3). 
Matthew discussed the role below, where a GP receptionist refused to access a GP for a requested MHA assessment. When she became increasingly obstructive, it resulted in Matthew invoking the role of a legal enforcer as follows:

I said you better listen very carefully to what I'm going to say to you now, 'I feel that you're obstructing me in my duty and I will be taking this further, please go away and get me a GP'. And they had one within 10 seconds. It's the only time I've done it but again you have to do it (Matthew, Interview 3).

The 'legal enforcer' role involved discussing the legal duties of the AMHP role with other professionals and involved parties; it focused on promoting people's rights and ensuring fair care and treatment from health professionals, who have a duty to respond appropriately to requests from AMHPs for medical assessment.

Diana used a metaphor in interview 2 to describe the 'legal enforcer' role as akin to that of a 'big bad wolf', highlighting the power in the role as a professional whom people fear 'Because what you're doing is horrendous, you're dragging somebody out of their home against their will'. Feeling like the 'big bad wolf' showed internal conflicts between this role and the role of 'advocate', where she was balancing professional dilemmas. She expressed feeling stuck between these two colliding value systems, highlighting the difference between what she wanted to do, 'put your arm around them', as opposed to what she must do, 'the right thing', i.e. detention under the MHA.

These multifarious legally oriented roles demonstrated the strong role salience participants had with the officially sanctioned role of 'legal applicant' but suggested how the role of 'legal applicant' embodied other nuanced roles that cross-cut other professional's jurisdictional boundaries. This finding situates additional nested roles through their enactment, within the role of 'legal applicant'. 


\section{'Custodian of Social Justice'}

The 'custodian of social justice' role involved advocacy skills and was inter-related to the 'quasijudicial' role in its legal focus. However, it differed in the sense of AMHPs acting as a promoter of individual human rights through a focus on upholding social justice, entwined with adopting social perspectives and values, rather than merely legal justice values. Social justice was distinguished from legal justice through participants' emphasis on understanding the impact of societal disadvantage on mentally ill individuals, on acting proportionately and in a least restrictive way of an individual's rights and freedoms under the HRA (1998). Caring for people, protecting individuals' human rights and working with other professionals to ensure this was upheld was a core element of this role. The seriousness attached by participants of enacting the 'custodian of social justice' role was illustrated by all participants' narratives. Simon's narrative below is chosen as a typical illustration of this role:

Because you make decisions about people's liberty really, you're making decisions and you're trying to do it by acting in their best interest, least restrictive ways, you know what can work (Simon, Interview 3).

Participants responded to the needs of vulnerable and diverse populations whose human rights were threatened by social and health inequalities, and redressed this where possible. However, their work was constrained by structural systems. Service users with serious mental health needs have poorer physical health, live in poverty, in poor housing, and are more likely to be unemployed or socially isolated, with poorer life expectancy (Marmott Review, 2010). This knowledge was applied when considering the impact of detention. In this role, participants made critical decisions about the least restrictive and most suitable context in which people should receive care and treatment, playing an essential, statutory role, in protecting people's human rights by promoting the principles of the Code of Practice (DoH, 2017).

This was illustrated as follows:

Obviously least restrictive is one of the core values of AMHPs of trying to care for people, of the care that they need that's least restrictive of their rights and their freedoms. That's the key thing, you know those human rights (Kate, Interview 1). 
Below, Tina recounted an event concerning a dispute with a psychiatrist who, on flimsy evidence, recommended detention. She described how she acted as a 'custodian' for an individual who she thought could be arbitrarily detained:

But it is worth the battle because that stops (them) going in, because they don't need to go in, but you've got to be able to stand up and say it, because if you don't, who's gonna say it for them (Tina, Interview 1).

Standing up for service users where transgression of the law was observed was a key aspect of the role. Demonstrating how AMHPs valued acting as a 'check and balance' within the English and Welsh mental health system.

The following roles which are advisory in their enactment will now be discussed; these are the roles of 'advocate' 'educator', 'and 'mediator'.

\section{Advisory roles}

\section{'Advocate'}

Related to the 'custodian of social justice' role was the 'advocate' role, enacted when representing the view of the service user rather than to act as a 'custodian of social justice'. This role was principally invoked to support counter-arguments to compulsory detention, through offering community alternatives to hospital admission. It was enacted to support individuals undergoing MHA assessment to express their views and wishes, thereby, ensuring their voice was heard, or when individuals were unable to advocate for themselves, due to mental incapacity:

I enjoy being the voice of people those who have no voice all or don't know how to articulate what they think, feel they've been submerged by professionals...We are paid to make it matter, otherwise we should go into another job, and if you can't do that, we can't stand up for the people, making it matter and bring about change and do the difficult stuff and walk in the shit, then we should walk away (Annette, Interview 2).

Here, Annette conveyed her passion for 'making it' matter and how this was a significant aspect of her and other AMHPs' roles. In discussing AMHPs who cannot 'bring about change' (albeit recognising this was difficult and they should 'walk away'), she was narrating a discourse of 
AMHP practice as intimately bound to the advocate role.

Evidence of minimising the power differentials between doctors and patients during MHA assessment was enacted in the 'advocate' role. Elizabeth discussed her enactment of the role to mitigate against the social exclusion of mentally ill individuals, using an example of a female with a severe learning disability, where she tried 'to advocate for her in the system whereby everybody has a criterion that seems to exclude rather than include' (Elizabeth, Interview 2). Dawn also suggested the advocate role was a strong element of her professional role, and stated 'I'm going to give them attention and devotion to get them to wherever it is they want to be, to stay where they are because they're happy, whatever it is, advocating for them, supporting them...that's what I do in my work' (Dawn, Interview 1). Here the use of the word 'devotion' emphasised that advocating was a means of enacting and expressing her professional care towards mentally ill individuals in similar ways to Annette. This was echoed by Tina and Kate:

I think it comes back again to making sure that people got some kind of voice that they can speak, that they're being listened to and being heard because sometimes that can get lost can't it (Tina, Interview 2).

In addition:

[The]AMHP is in a very strong position to advocate for the service user, and the importance of having a very rights-based or human rights-based approach (Kate, Interview 2).

The advocate role incorporated a service user led focus promoting the service users' perspective of the situation, ensuring that service users were listened to and that their voice was valued within the assessment process from the perspectives of the participants. This role has been supported by previous perceptions of ASWs acting as advocates (Quirk et al., 2000; Mankelow et al, 2002; Nathan and Webber, 2010) 


\section{'Educator'}

The role of 'educator' was foregrounded when AMHPs educated other professionals to acquire knowledge and legal literacy of the MHA (DoH, 2008a), its related regulations and code of practice (DoH, 2008a, 2008b). The 'educator' role was invoked to make MHA assessments run smoothly, when AMHPs advised General Practitioners of the grounds of mental disorder under section 1 of the Act (DoH, 2008a, 2008b) and on how to complete a medical recommendation. Elizabeth's example illustrated the role below:

We work with GPs and a lot of our role is... guiding GPs, because mental health isn't their thing for a lot of them. We do find ourselves...making sure they understand the process, because I don't think even they have very much training on mental health (Elizabeth, Interview 3).

AMHPs' enacted the 'educator role' when other professionals attempted to transgress the AMHPs' legal duties of ensuring patients safe conveyance to hospital. Particularly, with bed managers when advising them of the delegated legal duty to provide a hospital bed; in persuading bed managers to find a local bed due to the potential detrimental impact on an individual if they were admitted to a remote hospital bed away from family and friends; 'a lot of it is about helping them (other professionals) to understand our role' (Kate, Interview 3). As other professionals, arguably did not have a thorough understanding of the MHA, participants routinely educated others on the legal criteria and used this knowledge to reinforce legal boundaries.

\section{'Mediator'}

Professional mediation took place across organisational boundaries, within professional working arrangements, amongst multiple agencies and professional groups. It involved persuading professionals who expressed disagreement with participants in their AMHP role to reach an agreement regarding the outcome of the MHAA and was closely aligned with the educator role. Participants managed interaction between parties (in similar ways to the 'stage manager' role in Quirk 
et al., 2000), and facilitated sensitive communication that respected the private and confidential nature of their work.

Participants acted as sophisticated communicators in guiding other professionals through the process, characterised by broadening the range of possible solutions and the respectful way this should be achieved. They used various techniques such as dialogue and empathy, aiming to smooth the assessment process to secure the best outcome for service users, to make the bridges between different professional and organisational boundaries work productively:

I think the role from me is one of mediator, very much so and I think across the different organisations because sometimes you mediate professional responses. Sometimes you soften the responses between organisations to make those bridges work better. Because you know, you can get that kind of Mexican standoff almost, can't you, between some organisations? (Annette, Interview 3).

Much depended on the mediator's relational skills; it was not a neutral activity, it was value- laden for participants enacted through discursive actions within this role to 'make the wheel turn.' It enabled organisational systems to work better for AMHPs as boundary spanning professionals (Leah, 2018).

\section{'Therapist'}

Finally, participants enacted therapeutic approaches during MHA assessments. These approaches were conceptualised as a 'therapist', although it may not have been experienced as therapeutic to the individual being detained. This role comprised of a caring approach that was illustrated through the following narratives:

I will use my therapeutic skills to gain more information, to see if I can in any way work on whatever their issues are, advice, signposting, in a more informal way (Dawn, Interview 3).

It was often invoked in highly emotionally charged situations, to manage risk to self and others and to reduce the stress arising from the process of MHAA:

I think you can have a therapeutic effect using therapeutic rapport. The way that we communicate with people, some of the approaches we might use to help people to understand what's happening...I think using good interpersonal type counselling skills to give people the opportunity to ventilate ...that can feel therapeutic really...and I think we used CBT approaches and psychosocial interventions (Kate, Interview 3). 
The longer-term recovery of service users was an integral aspect of this role, so although the MHA assessment is 'horrendous' as Annette described it, it was also 'on some level... therapeutic even if it does end up in detention as well' (William, Interview 3). From a recovery perspective, it was present in the ways participants offered alternatives to detention for individuals, by encouraging individuals to engage with services to remain out of hospital, 'so it's therapy but broad' (Matthew, Interview 3).

\section{Discussion - A Jack of all Trades?}

It was evident that participants enacted hybrid roles. In authoring the self, participants made reflective choices about how they espoused and enacted their multifarious roles. Roles were not just achieved, they were enacted through engagement in an activity that entailed performance and in turn, recognition by others e.g. psychiatrists (Leah, 2018). The espoused roles were enacted in discursive spaces, within work-based conversations with other professionals involved in Mental Health Act work. The multifarious roles illustrated the complexities of participants' professional roles and were improvised and inter-related, with certain roles being more valued and socially desirable than others to AMHPs, service users and professionals who came within the orbit of MHA assessment.

Participants' practiced role adequacy; they were knowledgeable about their work, and role legitimacy, believing they had the right to address certain issues, driven by values of social and legal justice. This perceived right gave AMHPs power and leadership, although the degree of this varied depending on the enabling and constraining contexts of professional practice, including the relationships between others they worked with. The roles discussed were nested within the formally regulated legal role of the AMHP. They showed through complexity in working arrangements within and across AMHP jurisdictional boundaries how participants operated at the intersection of several disciplines, filling the 
liminal spaces of the roles other professionals should inhabit (Morriss, 2017; Leah, 2018, Vicary et al, 2018). Drawing on Bakhtin (1981) in Holland and Lave (2000), hybridisation of roles was a way of AMHPs as professionals taking an, 'authorial stance in the orchestration of multiple voices; refiguring the space of authorship, multiplying the possible way of identifying activity' (p.315).

Participants' work was attached to circumstantial societal change that showed their responses to contextual factors with 'their links with outside worlds... (being)... part of their professionalism' (Noordegraaf, 2007: p.771). Work that involved dealing with 'trade-offs' was a common feature, borne from managing service users' needs in the face of financial constraints and reduced capacities (McNicholl, 2015). Through hybrid roles participants showed they could respond to the uncertainties experienced during MHA assessment. This comprised of their ability to deal with risk using their expert knowledge.

Hybridised roles are especially relevant in occupations such as that of the AMHP, where meaningful connection is required between service users' public and private domains, and where there are multifaceted interactions that require linking 'street level work' worlds (Lipsky, 1980) with organisational and professional worlds (Noordegraaf, 2015). Such connections involve navigating multiple and competing requirements. AMHPs showed how they could deconstruct tensions by adapting or discarding roles contextually. This was where AMHP roles were crafted to meet the perceived demands of mental health work. These roles were rehearsed and refined during mental health work, influenced by numerous factors from law, policy, practice imperatives and professional organisational issues (NHS Digital, 2017; Romeo, 2017). The roles were hybridised as a response to the uncertainties experienced in MHA work, contextualised within broader working arrangements within risk societies (Evetts, 2006, 2013).

Professional work is changing (Noordegraaf, 2015, Stevens et al, 2018) and so too is the role of the AMHP. Enacting the multifarious roles illustrated involved participants collaborating, innovating, taking responsibility and managing resource capacities alongside manging professional repertoires 
that were at times, conflictual. It involved working across disciplines and adjusting their world view in situ across connected spheres.

AMHPs may perceive contradictory roles; however, they could be empowered to see this as a natural part of their work. Hybrid roles suggest a profession that is adaptable to societal change. AMHPs offer enrichment to the service they provided to individuals with acute mental health presentations in 'meaningfully managed' work (Noordegraaf, 2015: p.11). Such 'meaningfully managed' work enabled AMHPs to enact hybrid roles across diverse professional groups and organisations, demonstrating salience with previous conceptualisations of hybrid professionals within international contexts (Noordegraaf, 2007; Oliver, 2015). The roles discussed demonstrated how AMHP practised across broader boundaries, beyond the officially sanctioned legal role as the 'applicant'. Roles were practised at the intersection of health and social care systems, with AMHPs systematically nurturing complex infrastructures to create care and treatment outcomes that were underpinned by social perspectives that formed complex chains of discursive professional practice. AMHPs enacted roles that they ascribed to themselves and that others ascribed to them. In doing, so they conveyed what they want others to see, elaborated through recognition, value and experience. Working with the ambiguities and complexities of the multiple roles enacted, suggests that AMHPs are a jack of all trades, evident within the hybrid expertise and adaptability found. AMHPs were grappling with continual change. Their roles and responsibilities had become more demanding, and conflicts with other professionals occurred where priorities clashed. Mobilising the concepts of cross-cutting and nested roles suggests a more complex picture of the AMHP role. How participants contextualised their role had an impact upon how they made sense of their workplace and their place within broader organisational spheres. The HIP showed how AMHPs enacted nuanced roles, that were hybridised as a response to the uncertainties experienced in MHA work, that is part of working in risk societies (Evetts, 2006, 2013). The roles suggested how AMHPs responded to the complexity of mental health presentations that could not be confined to a neat discipline shaped box of AMHPs as 'legal applicants'. This is because individuals' complex mental health presentations cross complex 
professional and organisational boundaries and thus required AMHP responses to do the same (Hood, 2012; Leah, 2018).

There are nuances in enacting hybrid roles for AMHPs. While hybrid roles are useful for meeting complex demands, and negotiating the interface between various organisations and other mental health occupations, there are well documented challenges in providing an appropriate AMHP service (Allen, 2014). The HIP found that the conflicts noted in inter-disciplinary working arrangements tended to undermine AMHP decision making and exacerbate the negative experiences perceived by service users when there were false starts and delays in securing care and treatment provision e.g. bed and ambulance availability (Quirk et al., 2000; Leah, 2018). A recognition of the constraints that AMHPs work within is critical for understanding how AMHPs are positioning and adapting their roles, and how this is positioned within complex social and health care systems.

\section{Relatability, Validity and Limitations}

This was a small-scale qualitative study and the enactment of the hybrid roles found did not investigate whether some roles were more prevalent or important than others in participants' perceptions of their role enactment. The research can be analytically generalised, but broader AMHPs' perceptions of their roles cannot, given the HIPs contextual focus and small-scale nature. The participants may not have been representative of all AMHPs and may have been influenced by gatekeeper bias (Hammersley and Atkinson, 2007). The author was an insider researcher and participants may have presented themselves differently to an outsider researcher (Pillow, 2003). The study offers validity in relation to its relatability, as other AMHPs may relate to and value the findings herein (Bassey, 2001). The author made analytical generalisations based on the conceptual framework that was used as a lens for interpreting the research questions. However, these generalisations should 
be viewed in context and would require additional research to corroborate the phenomenon under examination. In conceptualising professional roles, the author acknowledges their dynamic nature and the subjectivities of participants' 'imagined' and 'experienced' perceptions of their roles (Billot, 2010). The study has examined the enacted multifarious roles of AMHPs. However, how AMHPs navigate and reconcile the tensions reported between the roles found requires further research. For example, how AMHPs resolved the tension between the duty to legally coerce, whilst also protecting individuals' human rights, witnessed between roles of 'quasi-judge' and the 'custodian of social justice' was not examined within the study. It would be interesting to examine in future research which roles were embedded more frequently and take the most priority in AMHP practice. A recognition of the constraints that AMHPs' work within is critical for understanding how AMHPs are positioning and adapting their roles, and how this is positioned within complex social and healthcare systems. It may be that AMHPs are experimenting with different roles as trials to not yet fully formed professional roles and identities (Ibarra, 1999). Research that considers how different roles may act as trials for embodied professional identities is suggested (Ibarra, 1999). The article adds to an emerging AMHP research base and offers opportunities for scholars and practitioners to extrapolate the findings to use for their own study and/or practice.

\section{Conclusion}

To conclude, the focus of this article has been on hybrid roles and has drawn upon the work of Quirk et al., (2000) in investigating multiple AMHP roles. It has been argued that AMHPs enact hybrid roles as hybrid professionals, evident within the research findings. This has challenged an overemphasis on the legalistic aspects of the role (Ramon, 2009) and recognised AMHPs expertise in enacting hybrid roles. Adapting to resource constrained environments through the enactment of multifarious roles shows how AMHPs can deal with conflicting demands, and how enacting hybrid 
roles is a means of AMHPs managing the "fragmentation of mental health work in contemporary risk societies' (Noordegraaf, 2015). 


\section{Acknowledgements}

I would like to thank Professor Hugh McLaughlin, Dr Lisa Morriss and Dr Jenny Fisher for their scholarly advice and support. 


\section{References}

Abbott A (1988) The Systems of Professions. An Essay on the Division of Expert Labor. Chicago. University of Chicago Press.

ADASS (2018) AMHPs, Mental Health Act Assessments \& the Mental Health Social Care workforce. Available at: https://www.adass.org.uk/national-findings-amhps-mental-health-actassessments-the-mental-health-social-care-workforce

Allen R (2014). The Role of the Social Worker in Adult Mental Health Services. London: The College of Social Work.

Bakhtin M (1981) The Dialogic Imagination: Four Essays by M.M. Bakhtin, in M E Holquist (eds.) (Emerson $\mathrm{C}$ and Holquist M trans). Austin: University of Texas Press.

Bassey M (2001) A Solution to the Problem of Generalisation in Educational Research: Fuzzy Prediction. Oxford Review of Education 27(1): 5-55.

Billot J (2010) The imagined and the real: Identifying the tensions for academic identity. Higher Education Research and Development 29(6): 709-721.

Blomgren M and Waks C (2015) Coping with contradictions: hybrid professionals managing institutional complexity. Journal of Professions and Organization 2(1): 78-102.

Byrkjeflot H and Kragh Jespersen P (2014). Three Conceptualizations of Hybrid Management in Hospital. International Journal of Public Sector Management, 27: 441-458. 
Croft C Currie G and Lockett A (2015). Broken Two Way Windows: An Exploration of Professional Hybrids, Public Administration, 93(3), 380-394.

Department of Health (2008a) Mental Health Act 1983. London: The Stationery Office.

Department of Health (2008b) Mental Health Act (A.M.H.P.) Regulations 2008, Schedule 1. London: The Stationery Office.

Department of Health Code of Practice (2017) Mental Health Act 1983. London: The Stationery Office.

Department of Health and Social Care (2018) Available at: https://www.skillsforcare.org.uk/NMDS$\underline{\text { SC-intelligence/Workforce-intelligence/documents/AMHPs-Briefing.pdf }}$

DeVerteuil G (2004) Systematic Inquiry into Barriers to Researcher Access: Evidence from a Homeless Shelter. Professional Geographer, 56(3): 372-80.

Evans L (2013) The Professional Status of Educational Research: Professionalism and Developmentalism in Twenty First-Century Working Life. British Journal of Educational Studies, 61(4): $471-490$

Evetts J (2002) New directions in state and international professional occupations. Work, Employment and Society 16(2): 339-351. 
Evetts J (2006) The sociology of professional groups: New directions. Current Sociology 54: 133143.

Evetts J (2013) Professionalism: Value and ideology. Current Sociology Review 61(5-6): 778-796.

Gregor C (2010) Unconscious aspects of statutory mental health social work: Emotional Labour and the Approved Mental Health Professional. Journal of Social Work Practice 24 (4): 429-43.

Hammersley M and Atkinson P (2007). Ethnography. Principles in Practice. Oxon: Routledge.

Hoff T J (2000) Professional Commitment Among US Physician Executives in Managed Care. Social Science and Medicine 50(10): 1433-44.

Hood R (2012) A critical realist model of complexity for interprofessional working. Journal of Interprofessional Care 26(1): 6-12.

Holland D and Lave J (2000) History in Person. Enduring Struggles, Contentious Practice, Intimate Identities. Santa Fe: School of American Research Press.

Ibarra (1999) Provisional Selves: Experimenting with Image and Identity in Professional Adaptation. Administrative Science Quarterly 44(4): 764-791.

Leah C (2018) Approved Mental health Professionals: Negotiating dialogic identities as hybrid professionals. Unpublished thesis awarded from the School of Environment, Education and Development, Faculty of Humanities, University of Manchester.

Lipsky M (1980) Street level bureaucracy, Dilemmas of the individual in public services. New York: Russell Sage Foundation. 
Macfarlane A and O'Reilly M D B (2012) Using a theory driven conceptual framework in qualitative health research. Qualitative Health Research 25(5): 607-608.

Mankelow R. Hughes P Britton F Campbell J Hamilton B and Wilson G (2002) The Experience and Practice of Approved Social Workers in Northern Ireland. British Journal of Social Work, 32, 443461.

Marmott M (2010) Fair Society, Healthy Lives: Strategic Review of Health Inequalities in England post 2010, The Marmot Review [Online] Available at:

http://www.instituteofhealthinqulaity.org/projects/fair-society-healthy-lives.the-marmott-review

McGivern G Currie G Ferlie E Fitzgerald L and Waring J (2015) Hybrid Manager - Professionals' Identity Work: The Maintenance and Hybridization of Medical Professionalism in Managerial Contexts. Public Administration 93: 412-432.

McNicholl A (2015) Mental health patients sent hundreds of miles as cuts leave little slack in the system, Community Care. Available at: www.communitycare.co.uk/2014/11/28/deathslinked-mentalhealth-beds-area-placements-rise-23-per-cent/

Mental Health (Northern Ireland Order 1986) accessed at: http://www.nihrc.org/advice-foryou/mental-health

Morriss L (2017) Being Seconded to a Mental Health Trust: The Invisibility of Mental Health Social Work. British Journal of Social Work 47(5): 1344-1360. 
Nathan J and Webber M (2010). Mental health social work and the bureau-medicalisation of mental health care: identity in a changing world. Journal of Social Work Practice 24(1): 15-28.

NHS Digital (2017) Mental Health Act Statistics, Annual Figures: 2016-17. Available at: https://digital.nhs.uk/data-and-information/publications/statistical/mental-health-act-statistics-annualfigures/mental-health-act-statistics-annual-figures-2016-17-experimental-statistics.

NHS Benchmarking Network and ADASS (2018) Social Care National Report AMHPs, Mental Health Act Assessments \& the Mental Health Social Care workforce. Available at: https://www.adass.org.uk/media/6428/nhsbn-and-adass-social-care-national-report.pdf.

Noordegraaf M (2007) From 'pure' to 'hybrid' professionalism: Present day professionalism in Ambiguous Public Domains. Administration and Society 39(6): 761-785.

Noordegraaf M (2015) Hybrid professionalism and beyond: (New) Forms of public professionalism in changing organisational and societal contexts. Journal of Professions and Organization 2(2): 187206.

Oliver C (2015) Social Workers as Boundary Spanners: reframing our professional identity for interprofessional practice. Social Work Education 32(6): 773-784.

Pillow W (2003) Confession, catharsis or cure? Rethinking the uses of reflexivity as methodological power in qualitative research. Qualitative Studies in Education 16(2): 175-196.

Quirk A Lelliott P and Audini B (2000) Performing the Act: A Qualitative Study of the Process of Mental Health Act Assessments. Glasgow: MRC Social and Public Health Sciences Unit. 
Ramon S (2009) Adult Mental Health in a Changing International Context: The Relevance to Social Work. British Journal of Social Work 39 (8): 1615-1622.

Ritchie J and Spencer L (1993) Qualitative data analysis for applied policy research in Bryman, A. and Burgess R (1994) (eds). Analyzing Qualitative Data. New York: Routledge. pp.173-194.

Romeo L (2017) Annual Report by the Chief Social Worker for Adults 2017-18. London: Department of Health.

Schon D (1983) The Reflective Practitioner. New York: Basic Books.

Spyridonidis D Hendy J and Barlow J (2015) Understanding Hybrid Roles: The Role of Identity Processes amongst Physicians. Public Administration 93(3): 395-411.

Stevens M Martineau S Manthorpe J Steils N and Norrie C (2018) Final report - Who wants to be an AMHP? London. Social Care and Social Work Research Unit, Kings College London.

The Florida Mental Health Act (1971) 'Baker Act'. Available at: http://archive.flsenate.gov/data/Publications/2009/Senate/reports/interim_reports/pdf/2009-105cf.pdf The Mental Health (Compulsory Assessment and Treatment) Act (1992) New Zealand. Available at: https://www.health.govt.nz/publication/guidelines-mental-health-compulsory-assessment-and$\underline{\text { treatment-act-1992 }}$

TW v Enfield Borough Council (2014). EWCA Civ 362 (2014) MHL0256. Available online at: http://www.mentalhealthlaw.co.uk/TW_v_Enfield_Borough_Council_(2014)_EWCA_Civ_362,_(201 4) MHLO 26. 
Vicary S Young A Hicks S (2018) ‘Roll Over’ or Role Over? Dirty Work, Shift and Mental Health Act Assessment. British Journal of Social Work 0: 1-20.

Vygotsky L S (1980) Mind in society: The development of higher psychological processes. Cambridge, USA. Harvard University Press.

Walter U M (2003) Towards a Third Space: Improvisation and Professionalism in Social Work. The Journal of Contemporary Human Services 84(3): 17-322.

Waring J (2015) Mapping the Public Sector Diaspora: Towards a Model of Inter-Sectoral Cultural Hybridity Using Evidence from English Healthcare Reforms. Public Administration 93(3): 345-62.

Wittchen HU, et al (2011) The size and burden of mental disorders and other disorders of the brain in Europe 2010. Journal of European Neuropsychopharmacol 21(9): 655-79.

Yin R K (2014) Case Study Research. (7th edn.) London: Sage. 
Table 1: Demographic characteristics of participants

\begin{tabular}{|c|c|c|c|}
\hline Participant & $\begin{array}{l}\text { Professional } \\
\text { background }\end{array}$ & Role/Workplace & $\begin{array}{l}\text { No. years in AMHP } \\
\text { practice }\end{array}$ \\
\hline Elizabeth & social worker & $\begin{array}{l}\text { care coordinator, best interest } \\
\text { assessor, adult community mental } \\
\text { health team } \\
\text { site } 1\end{array}$ & 11 \\
\hline Dawn & $\begin{array}{l}\text { occupational } \\
\text { therapist }\end{array}$ & $\begin{array}{l}\text { care coordinator, community mental } \\
\text { health homeless team } \\
\text { site } 1\end{array}$ & 5 \\
\hline Kate & social worker & $\begin{array}{l}\text { care coordinator, best interest } \\
\text { assessor, later life community mental } \\
\text { health team } \\
\text { site } 2\end{array}$ & 9 \\
\hline Simon & nurse & $\begin{array}{l}\text { care coordinator, deputy } \\
\text { manager, community mental health } \\
\text { team } \\
\text { site } 1\end{array}$ & 5 \\
\hline Tina & social worker & $\begin{array}{l}\text { senior social worker, care coordinator, } \\
\text { mental health city wide service } \\
\text { site } 2\end{array}$ & 17 \\
\hline Matthew & nurse & $\begin{array}{l}\text { care coordinator, deputy manager, } \\
\text { crisis home treatment team } \\
\text { site } 3\end{array}$ & 6 \\
\hline Diana & social worker & $\begin{array}{l}\text { senior mental health social worker, } \\
\text { care coordinator, mental health city } \\
\text { wide service } \\
\text { site } 2\end{array}$ & 20 \\
\hline Bernie & social worker & $\begin{array}{l}\text { senior mental health practitioner, care } \\
\text { coordinator, mental health city wide } \\
\text { service } \\
\text { site } 2\end{array}$ & 9 \\
\hline William & social worker & $\begin{array}{l}\text { care coordinator, best interest } \\
\text { assessor, early intervention team } \\
\text { site } 3\end{array}$ & 9 \\
\hline Annette & social worker & $\begin{array}{l}\text { local authority commissioner } \\
\text { site } 3\end{array}$ & 11 \\
\hline
\end{tabular}

